\title{
Improving Performance of Fit among Strategies by Using Internet of Things Sensing Architecture
}

\author{
Shih-Fu Sung, ${ }^{1}$ Yue-Yang Chen, ${ }^{2 *}$ Hui-Ling Huang, ${ }^{3}$ \\ Tsai-Pei Liu, ${ }^{4}$ and Kuo-Chiang Hung ${ }^{5}$ \\ ${ }^{1}$ Department of Information Management, I-Shou University, \\ No. 1, Sec. 1, Syuecheng Rd., Dashu District, Kaohsiung City 84001, Taiwan \\ ${ }^{2}$ Department of Business Administration, I-Shou University, \\ No. 1, Sec. 1, Syuecheng Rd., Dashu District, Kaohsiung City 84001, Taiwan \\ ${ }^{3}$ Department of Business Administration, Chang Jung Christian University, \\ No. 1, Changda Rd., Gueiren District, Tainan City 71101, Taiwan \\ ${ }^{4}$ Department of Distribution Management, National Taichung University of Science and Technology \\ No. 129, Sec. 3, Sanmin Rd, North Dist., Taichung City 404, Taiwan \\ ${ }^{5}$ Department of Information Engineering, I-Shou University, \\ No. 1, Sec. 1, Syuecheng Rd., Dashu District, Kaohsiung City 84001, Taiwan
}

(Received May 29, 2019; accepted June 3, 2020)

Keywords: Internet of Things (IoT), sensing architecture, fit

As academics and managers gradually developed interest in the importance of operational strategy, research in the field has increased significantly over the past decades. The research stream in operational strategies has focused on the alignment of strategic priorities and its impact on performance, and the importance of the alignment between strategies. Marketing strategy is a set of integrated decisions and actions by which a business expects to achieve its marketing objectives and meet the value requirements of its customers by using an advanced information technology (IT)/information system (IS) to collect data or information. Thus, the fit among business, IS, marketing, and manufacturing strategies has emerged as a critical issue for firms. Therefore, the main purpose of this study is to explore the impact of corporate, manufacturing, marketing, and IS strategies on business performance. We propose the strategy of holistic perspectives to confirm the legitimacy of the proposed model, and we improve the efficiency of enterprise management in the use of the Internet of Things (IoT) sensing architecture. The results showed that the fit of business, manufacturing, marketing, and IS strategies has a significant impact on business performance. Therefore, the application of the IoT cloud architecture can be used to improve the operational efficiency of enterprises.

\section{Introduction}

In recent years, with the rise of business management strategy in innovative thinking, business professional operators and experts have begun to focus on how to effectively develop strategies to improve or even maximize organizational performance. Therefore, business

*Corresponding author: e-mail: chenray60@gmail.com

https://doi.org/10.18494/SAM.2020.2486 
strategy has been an important strategic resource in recent years. ${ }^{(1)}$ Global companies are currently facing an environment of economic volatility, especially when manufacturers deal with the company's business strategy. It is necessary to obtain an in-depth understanding of the nature of the current situation of an enterprise and to use appropriate operational strategies to replace the previous complex process mode. From a strategic point of view, business owners are still looking for a better way to increase their firm's competitive advantage, since it has been proven that the operational strategy must be aligned with other functional strategies to attain a superior organizational performance. ${ }^{(2-4)}$

Regardless of whether companies specialize in manufacturing or services, marketing activities usually act as the channel of communication between the marketing environment and customer preferences and usually deal with revenue maximization, whereas manufacturing is usually responsible for receiving the design for production and cost minimization. ${ }^{(5)}$ As a firm that may contain different service modules as well as to solve the problem of confusion, it is also important for manufacturing companies to employ the right strategy to optimize the marketing strategy in conjunction with the production strategy. ${ }^{(6)}$ Although marketing and manufacturing are organizationally separate in most firms, without their effective coordination, they could potentially jeopardize the organization's survival in the marketplace. ${ }^{(7)}$ Recently, many companies have switched from vertical to horizontal resource integration by using advanced technologies, especially with Internet of Things (IoT) technologies, and thus in the enterprise strategy, it is even more important to integrate the manufacturing, marketing, and information system (IS) strategies into business strategy. ${ }^{(8)}$ Specifically, the aim of this study is to verify the impact of fit among the business, manufacturing, marketing, and IS strategies on enterprise performance. The research model will be built into indicators involving sensors applying IoT technology to improve the management of enterprise performance.

\section{Theoretical Background}

\subsection{Fit}

The common basic proposition of fit is that organizational performance is a consequence of the fit between two or more factors, such as the fit between the organizational environment, strategy, structure, system, style, and culture. ${ }^{(9)}$ In this study, the terminology of fit and its concept are analogical with the term of strategic alignment. According to Venkatraman, ${ }^{(10)}$ fit has six different perspectives: matching, moderation, mediation, gestalts, covariation, and profile deviation. The six perspectives can be classified into two categories according to the number of variables being simultaneously examined. Accordingly, fit as matching, moderation, and mediation can be categorized into the reductionist perspective, whereas fit as gestalts, covariation, and profile deviation can be regarded as the holistic perspective. ${ }^{(1)}$

According to Bergeron et al. ${ }^{(12)}$ the fit with the covariation approach is applicable to theory testing. Accordingly, we adopted this perspective to test the effect of fit. The purpose of using the covariation perspective was to prove that the existence of an integrated fit relationship among these four related variables is significant for performance. As aforementioned, the 
purpose of this study is to analyze the performance implications of business strategy orientation, manufacturing strategy orientation, marketing strategy guidance, and IS orientation. It is found that the adjustment from the perspective of strategy will help to improve the performance of enterprises. Therefore, business strategy should be able to be more diverse in combination with other strategic factors in order to synergize all of the resources with an organization. ${ }^{(13)}$

\subsection{Business strategy}

According to previous studies, there are three widely used business strategic frameworks: (1) Miles and Snow's ${ }^{(14)}$ generic typology, (2) Porter's ${ }^{(15)}$ competitive strategy model, and (3) the fine-grained framework of Venkatraman, ${ }^{(13)}$ among which Miles and Snow's typology is the most popular stream of business strategy research. ${ }^{(16)}$ Drawing on the perspective proposed by Miles and Snow, ${ }^{(14)}$ Venkatraman's ${ }^{(17)}$ strategic orientation of business enterprises (STROBE) operationalization of business strategy is another widely used framework. He defined STROBE as "... the general pattern of various means employed to achieve the business goals, with a particular emphasis on the business-unit level of the organizational hierarchy." To conceptualize and construct the strategy constructs, he used four theoretical questions that are critical in strategic management research, namely, those related to scope, hierarchical level, domain, and intentions versus realizations. Through the consideration of means, business level analysis, and broad, realized, and holistic perspectives of strategy, six important dimensions of strategic orientation are proposed in Venkatraman's ${ }^{(17)}$ study: aggressiveness, analysis, defensiveness, futurity, proactiveness, and risk aversion. These constructs demonstrated adequate reliability and validity to serve as useful measures in strategy research to test the theoretical relationships, and were found to have a significant impact on business performance. ${ }^{(13)}$

\subsection{Manufacturing strategy}

In the manufacturing industry, manufacturing strategy plays a critical role in decisionmaking. Good manufacturing strategy for enterprises will lead to improved performance and enhanced business efficiency. However, it will cause serious deficits and hoarding of too much commodity. The electronics industry is sure to follow. Hayes and Wheelwright ${ }^{(18)}$ indicated that the manufacturing strategy process, content, and implementation determine how resources and capabilities are to be deployed within organizations to complement the business strategy. The major benefit of manufacturing strategy is that it provides a means for focusing the attention of corporate management on manufacturing concerns. Achieving cross-industry or interindustry cooperation to improve operating conditions and market competitiveness is an important strategic issue facing not only large enterprises but also small and medium enterprises in their collaborative planning strategy to compete in markets. For example, Corbett and Van Wassenhove ${ }^{(19)}$ argued that a manufacturer's product development is a process of knowledge creation; it is also necessary from the perspectives of strategic and cost-effective control to develop long-term cooperation to achieve competitive advantages. 


\subsection{Marketing strategy}

For contemporary companies, marketing and channel decisions are important. Without them, firms' efforts to attract customers are likely to be inefficient and dysfunctional. The focus of marketing strategy should be making sure that the marketed products and services meet customer needs and developing long-term and profitable relationships with those customers. However, before that, the products must pass a rigorous marketing test. If it is successful, it will effectively enhance the company's performance; if it fails, it will result in making the product stagnant, seriously affecting the company's profits.

As organizations have limited resources, market segmentation and targeting are necessary for them to commit limited resources to satisfy a particular customer group. In this vein, marketing orientation is considered by many as a measure of the behaviors and activities that reflect the marketing concept. ${ }^{(20)}$ However, marketing is not only a strategy or a concept, but a philosophy that is a cornerstone of a successful firm's culture. ${ }^{(20)}$ A well-defined marketing strategy could lead firms to better understand and meet the needs of their target customer groups by putting customers at the center of the firm's operations and strategy formulation. ${ }^{(21)}$

\subsection{IS strategy}

Long-term competitive advantages with a strategic IS are important strategic competitive weapons, which have been affirmed by most management scholars. However, much of the computer hardware and software, and even information services, at the core of an IS can be purchased. Since these products and services can create competitive advantages for a company, its competitors can also follow suit, until the opponent's advantage disappears. Since individual organizations have their own unique resources to build up a specific strategy, it will have an impact on information development decisions. Thus, the valuation of the system should not be limited to systemic benefits in the current environment, but rather to the measurement of its value with a longer-term and broader perspective. In addition, the competitive advantage of a strategic IS cannot be attributed solely to the computer systems used by them, but to the combined performance of computers, management systems, users, and so on. A good IS strategy can effectively improve the performance of enterprises in management. In the industrial chain, the IS is often a key factor for success. The IS is already an important asset of an enterprise. With a high degree of access to software and hardware, by investment, companies can rapidly and considerably construct information technology (IT) devices. When enterprises can combine and use management information related resources and create a unique IT capacity, they can obtain better organizational performance. Moreover, the full implementation of enterprise information can also enhance the performance of enterprises in the implementation of projects. 


\subsection{IoT}

IoT technologies have been widely adopted in our daily lives and are used in small personal devices, such as smart watches, as well as in large machines in factories, allowing their connection and exchange of information through IoT. IoT can be regarded as a paradigm in which computing and networking capabilities are embedded in any kind of conceivable object. ${ }^{(22)}$

Sensors are indispensable in the development of IoT. These sensors can collect and send production and customer information to facilities that respond to this information. IoT applications can benefit a wide array of industries, including services, entertainment, healthcare, retailing, and manufacturing. By employing IoT, firms can use the ubiquity it provides as another channel for the distribution of their traditional services, as a method to improve these services, or as a means to launch new services. ${ }^{(23)}$

\subsection{Hypothesis development}

In recent years, scholars and practitioners have tried to find the relationships between operational strategies within firms. ${ }^{(24)}$ Manufacturing companies actively adjust their manufacturing strategy and resources according to the ever-changing market to reduce the operational cost. Manufacturing strategy has been found to provide higher performance if it is employed with a well-established IS strategy. ${ }^{(25)}$ In addition, the contributions of modern business strategy have come from a broad range of disciplines, and manufacturing is an indispensable part of business strategy. Studies have found that aligning manufacturing and business strategies will contribute to the improvement of business performance and business objectives. ${ }^{(3,4)}$ Manufacturing strategy is linked to business strategy through market requirements, ${ }^{(26)}$ and market requirements are crucial to manufacturing strategy ${ }^{(27)}$ because order-qualifying and order-winning criteria win orders from customers. ${ }^{(28)}$ Since manufacturing strategy becomes aligned to the external environment when business and manufacturing strategies are linked consistently, ${ }^{(26,29-31)}$ manufacturing strategy should be involved in strategic orientation and implementation. ${ }^{(32)}$ In response to the rapid change in the hypercompetitive external business environment, strategists particularly advocate that manufacturing and marketing work together to speed up and improve the quality of strategic decision making. This is particularly true when IoT technologies have been adopted and equipped in the marketplace and in businesses with both indoor and outdoor asset tracking. ${ }^{(33)}$ The efficient use of IoT will improve operational efficiency owing to its capability to gather and explicate big data and automate connections among machines. Thus, technology-based employment should be aligned with business strategy and other related operational strategies. ${ }^{(34)}$

Consequently, our research tries to shed light on the fit effect of business, marketing, manufacturing, and IS strategies. The research model is shown in Fig. 1 and the following hypothesis is proposed: 


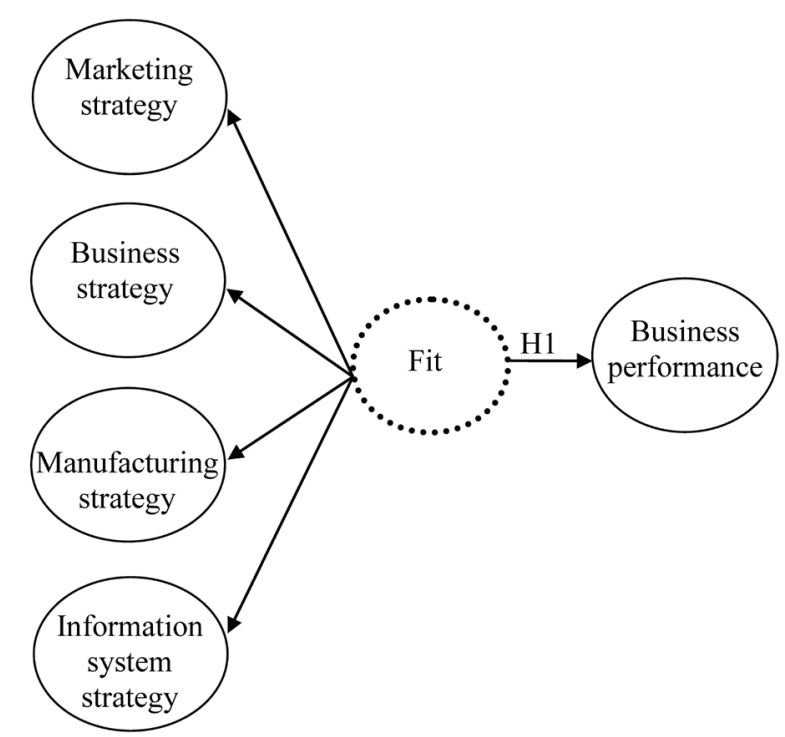

Fig. 1. Fit model. H1: Fit among business, manufacturing, marketing, and IS strategies has a significant and positive direct effect on business performance.

\section{Research Methodology}

\subsection{Statistical analysis method}

We used SPSS 20.0 and the structural equation modeling (SEM) of confirmation factor analysis (CFA) to verify the reliability and validity of each construct. Model estimation was performed using the maximum likelihood fit function and a sample correlation matrix. CFA involves the analysis of the measurement model, which demonstrated that the measurement model had sufficient levels of validity and reliability. ${ }^{(35)}$

The fit as covariation perspective outlined that the effect of a single strategy variable is limited, and thus we explore a set of internalized properties that are presented by the relevant derivative of the theory, and this internal consistency will have an impact on performance. Internal consistency is the concept of policy matching. According to Venkatraman, ${ }^{(13)}$ even though the covariation approach can be modeled as exploratory factor analysis (EFA) and CFA, the latter is preferred as a tool and testing method to examine fit as covariation. In the analysis, the strategy can be regarded as a latent variable, indicating that other attributes and effects are manifested by the combination of other corresponding anterior variables. ${ }^{(10)}$ Second-order factor analysis can be used to validate the proposed model in this study. According to Bergeron et al., ${ }^{(12)}$ the covariant model applies to the detection of the theory, so we use this view to detect and demonstrate the effects of business, manufacturing, marketing, and IS strategies.

\subsection{Measurement item development}

Five constructs were measured in this study: business, manufacturing, marketing, IS strategies, and business performance. The sixth construct, fit, is regarded as a latent variable 
for the four antecedent strategies mentioned above. A multiple-item method was used to develop questionnaires. Each item was based on a 5-point Likert scale ranging from 1 'strongly disagree' to 5 'strongly agree'. Wherever possible, to ensure measurement validity, we adopted previous well-established research instruments with minor changes in wording. Most of the independent and dependent variables were operationalized on the basis of the related existing literature.

We use the definition of Olsen et al. ${ }^{(36)}$ to define marketing strategy behavior as a strategic organization to guide employee behavior to achieve business goals. This study uses the marketing strategy behavior scale developed by Olsen et al. ${ }^{(36)}$ with 26 items and 10 variables.

We define manufacturing strategy as "the choice of manufacturers for competitive priorities and the development of manufacturing advantages", including product quality, delivery reliability, process flexibility, and cost elements, and the items were selected from Ward and Duray, ${ }^{(31)}$ which had a total of 15 questions.

This study is based on Venkatraman's ${ }^{(17)}$ definition of business strategy orientation, which defines business strategy as "a means of achieving organizational goals and a business model and, in particular, a hierarchy of institutions at the organizational level." We use the scales proposed by Sabherwal and Chan, ${ }^{(37)}$ including the following six elements: defensiveness, analysis, risk aversion, proactiveness, futurity, and aggressiveness. A total of 18 questions were used.

An IS focus on an IT in the system of enterprise-oriented applications, and it is often associated with the strategic relationship between business strategies. This study, based on the study of Sabherwal and Chan, ${ }^{(37)}$ distinguishes IS strategy from four subconstructs, namely, manufacturing support systems, interorganizational systems, market ISs, and strategic decision support systems, with a total of 17 questions.

We define business performance in accordance with the definition of Venkatraman: (13) "to achieve the goals of the business, the use of the resources and efforts of the organization in terms of growth and profitability." This measurement is divided into growth and profitability. A total of eight items are used.

\subsection{Data collection}

Primary data were collected through a cross-sectional mailed survey. Mailing lists were pooled from the China Credit Information Service, which includes the top 5000 companies in the manufacturing industry and the top 500 companies in the service industry in Taiwan. These companies were chosen for being the best performing companies in Taiwan within the field.

The total number of questionnaires collected in this study was 142. Excluding three invalid questionnaires, the actual number of questionnaires was 139, and the effective response rate was $11.39 \%$. The distribution of the samples is shown in Table 1. It can be seen from the table that companies with a size of 100 to 500 account for $45.3 \%$ of the total. Respondents include various positions, such as senior, middle, and junior managers, and so on. Nearly $61 \%$ of the respondents had more than six years of experience in service companies. The respondents who participated in the survey had sufficient experience and knowledge to complete the questionnaire. 
Table 1

Basic information on samples collected from questionnaire.

\begin{tabular}{|c|c|c|}
\hline Variable & Frequency & Percentage $(\%)$ \\
\hline \multicolumn{3}{|l|}{ 1. Industry } \\
\hline Manufacturing & 113 & 81.3 \\
\hline Service industry & 26 & 18.7 \\
\hline \multicolumn{3}{|l|}{ 2. Company size (number) } \\
\hline 100 people or less & 27 & 19.4 \\
\hline $100-500$ & 63 & 45.3 \\
\hline $500-1000$ & 28 & 20.1 \\
\hline More than 1000 people & 21 & 15.1 \\
\hline \multicolumn{3}{|l|}{ 3. Position } \\
\hline Senior supervisor & 6 & 4.3 \\
\hline Middle supervisor & 70 & 50.4 \\
\hline First-line supervisor & 28 & 20.1 \\
\hline General staff & 33 & 23.7 \\
\hline Other positions & 2 & 1.4 \\
\hline \multicolumn{3}{|l|}{ 4. Years of company service } \\
\hline Less than one year & 4 & 2.9 \\
\hline $1-2$ years & 17 & 12.2 \\
\hline $3-5$ years & 33 & 23.7 \\
\hline $6-10$ years & 28 & 20.1 \\
\hline More than 10 years & 57 & 41.0 \\
\hline \multicolumn{3}{|l|}{ 5. Education } \\
\hline Junior high school & 0 & 0.0 \\
\hline Senior (vocational) high school & 13 & 9.4 \\
\hline Junior college & 30 & 21.6 \\
\hline University & 59 & 42.4 \\
\hline Masters or above & 37 & 26.6 \\
\hline \multicolumn{3}{|l|}{ 6. Gender } \\
\hline Male & 101 & 72.7 \\
\hline Female & 38 & 27.3 \\
\hline \multicolumn{3}{|l|}{ 7. Age } \\
\hline Below 20 years old & 0 & 0.0 \\
\hline 21-30 years old & 21 & 15.1 \\
\hline $31-40$ years old & 56 & 40.3 \\
\hline $41-50$ years old & 42 & 30.2 \\
\hline Over 51 years old & 20 & 14.4 \\
\hline
\end{tabular}

\section{Research Results and Findings}

\subsection{Measurement model, reliability, and validity analysis}

SEM with the LISREL technique was used to assess the measurement and fit models. The validity of the research constructs was assessed by the estimation and respecification of the measurement model by CFA.

The first step was to assess the strength of measurement between items and associated constructs. Five measurement models were estimated. In each estimated model, items that demonstrate cross loadings, load, poor loadings, and poor reliability were dropped and the 
model was re-estimated. This was done to ensure that data are a good fit with the measurement. We used the threshold of 0.5 for factor loading assessment. ${ }^{(38)}$ The results show that the factor loading for each variable is greater than the recommended threshold of 0.5. In addition, the ratio of chi-square to the degree of freedom in each measurement of the study ranges from 1.14 to 2.95, which is less than the threshold of 3. The adjusted goodness of fit Index (AGFI) values range from 0.80 to 0.84 , which are more than 0.80 , and the comparative fit index (CFI) values range from 0.88 to 0.93 . The normed fit index (NFI) values range from 0.90 to 0.98 , which are acceptable, and the non-normed fit index (NNFI) values range from 0.83 to 0.98 , which are also acceptable. Finally, the standardized root mean square residual (SRMR) values range from 0.020 to 0.047 , meeting the acceptable level of less than 0.08 . Overall, the model demonstrated a good fit between the measurement pattern of each model and the data.

The reliability of the measurement was measured using Cronbach's $\alpha$. We also used CFA to calculate the composite reliability (CR). Table 2 shows that Cronbach's $\alpha$ values range from 0.76

Table 2

Results of reliability analysis.

\begin{tabular}{|c|c|c|c|}
\hline Variable & Number of questions & Cronbach's $\alpha$ & CR \\
\hline Marketing strategy & & 0.93 & 0.94 \\
\hline Marketing research & 3 & 0.92 & 0.92 \\
\hline Segmentation & 4 & 0.87 & 0.87 \\
\hline Product line depth & 3 & 0.77 & 0.79 \\
\hline Product innovation & 3 & 0.81 & 0.80 \\
\hline Service quality & 4 & 0.82 & 0.81 \\
\hline Premium pricing & 3 & 0.81 & 0.81 \\
\hline Selective distribution & 2 & 0.80 & 0.80 \\
\hline Advertising & 7 & 0.88 & 0.87 \\
\hline Personal selling & 5 & 0.91 & 0.92 \\
\hline Promotion support & 2 & 0.85 & 0.85 \\
\hline Manufacturing strategy & & 0.90 & 0.89 \\
\hline Product quality & 4 & 0.92 & 0.91 \\
\hline Delivery reliability & 2 & 0.88 & 0.88 \\
\hline Process flexibility & 5 & 0.86 & 0.83 \\
\hline Cost & 4 & 0.88 & 0.87 \\
\hline Business strategy & & 0.93 & 0.91 \\
\hline Defensiveness & 4 & 0.93 & 0.87 \\
\hline Analysis & 3 & 0.90 & 0.88 \\
\hline Risk aversion & 3 & 0.76 & 0.75 \\
\hline Proactiveness & 3 & 0.86 & 0.83 \\
\hline Futurity & 2 & 0.81 & 0.79 \\
\hline Aggressiveness & 3 & 0.82 & 0.81 \\
\hline IS strategy & & 0.97 & 0.98 \\
\hline Manufacturing support sys. & 6 & 0.89 & 0.90 \\
\hline Interorganizational systems & 4 & 0.96 & 0.96 \\
\hline Market IS & 4 & 0.97 & 0.97 \\
\hline Decision support system & 3 & 0.94 & 0.94 \\
\hline Business performance & & 0.94 & 0.92 \\
\hline Growth & 3 & 0.91 & 0.91 \\
\hline Profitability & 5 & 0.93 & 0.93 \\
\hline
\end{tabular}


to 0.97 , and the $\mathrm{CR}$ values of the variables range from 0.75 to 0.98 , demonstrating good internal consistency. Thus, we demonstrate good internal consistency of reliability.

In addition, discriminant and convergent validity can be assessed using the average variance extracted (AVE) estimate proposed by Fornell and Larcker. ${ }^{(35)}$ As can be seen in Table 3, variance extracted estimates for any pair of factors were compared with the square of the correlation between the two constructs. If both variance extracted estimates are greater than the square of the correlation, then discriminant validity is demonstrated. The results of the variance extracted tests show that discriminant validity is supported, since each square of the correlation is less than both the applicable variance extracted estimates. In addition, the AVE for each dimension is above 0.5. Thus, the construct also demonstrated a reasonable degree of convergent validity.

Finally, common method variance may be a concern owing to the fact that the data for all the constructs were collected by the same method. Thus, we evaluated this potential problem by Harman's one-factor test on all items. ${ }^{(39)}$ If common method bias exists, either a single factor will emerge, or one general factor will account for most of the covariance in the independent and criterion variables. The results showed that all components were extracted with their eigenvalues greater than 1 , accounting for $75.23 \%$ of the total variance for all variables. The first factor only accounted for $39.42 \%$ of the variance. This indicated that common method variance was not a major problem in this study.

\subsection{Hypothesis testing}

According to Venkatraman, ${ }^{(10,11)}$ the fit in the present research can be specified as a secondorder construct derived from the four antecedents. Business performance is also considered as a second-order construct composed of growth and profitability. According to Venkatraman, ${ }^{(10)}$ although the covariation approach can be modeled as EFA and CFA, CFA is preferred for testing fit as a covariation model. Following the methodology proposed by Venkatraman, ${ }^{(10)}$ we used a second-order confirmatory factor model to test the fit effect among marketing, business, manufacturing, and IS strategies on business performance.

As can be seen in Fig. 2, the fit model explains 53\% of the variance in business performance, demonstrating the importance of strategic alignment in business performance in terms of growth and profitability. The effect $(\gamma=0.73, p<0.001)$ strongly supports the performance implications of fit. Overall, the fit statistics indicate good fit of the model with the data collected from the validated measures. Therefore, according to the results, $\mathrm{H} 1$ is supported. 


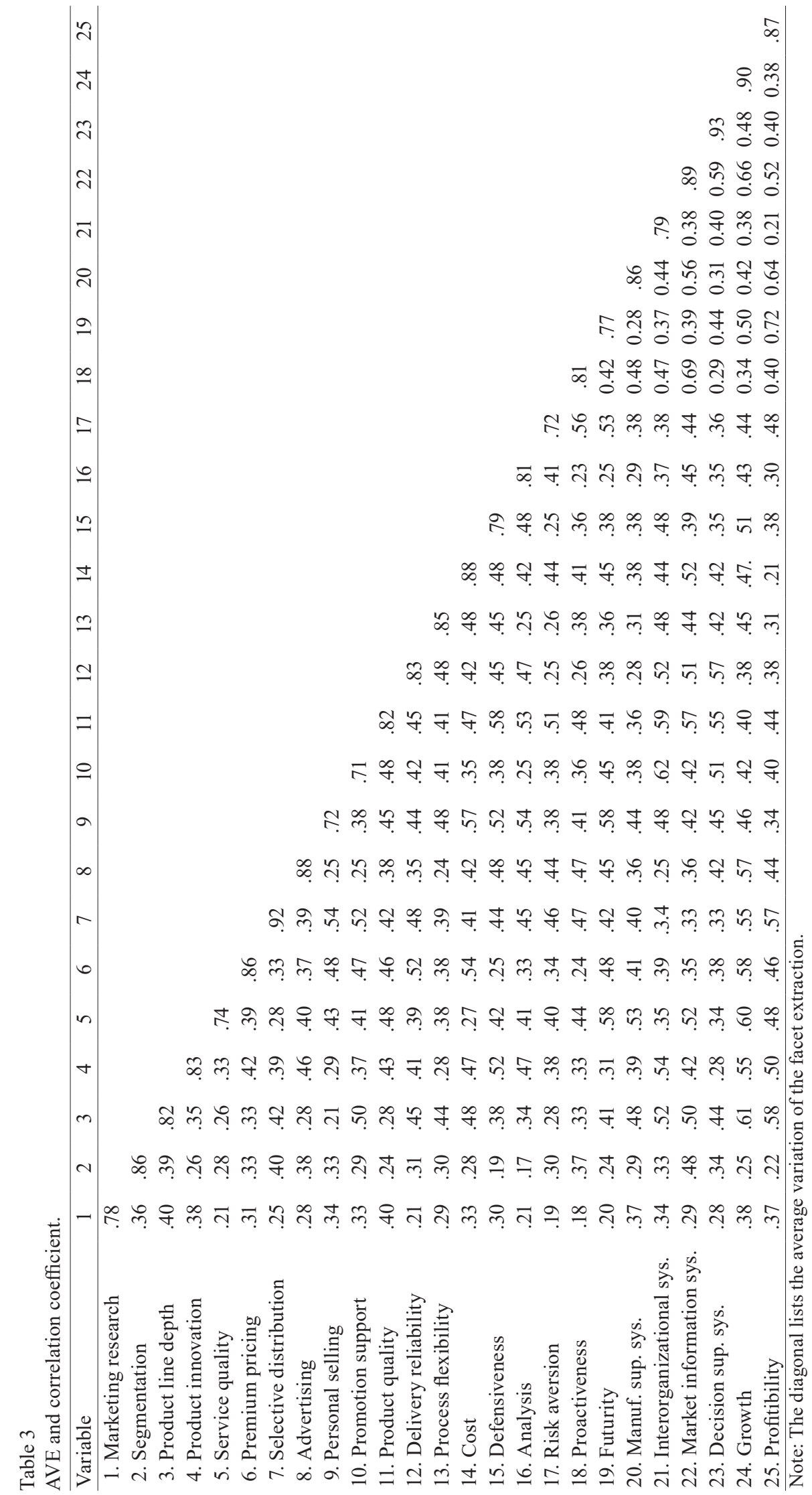




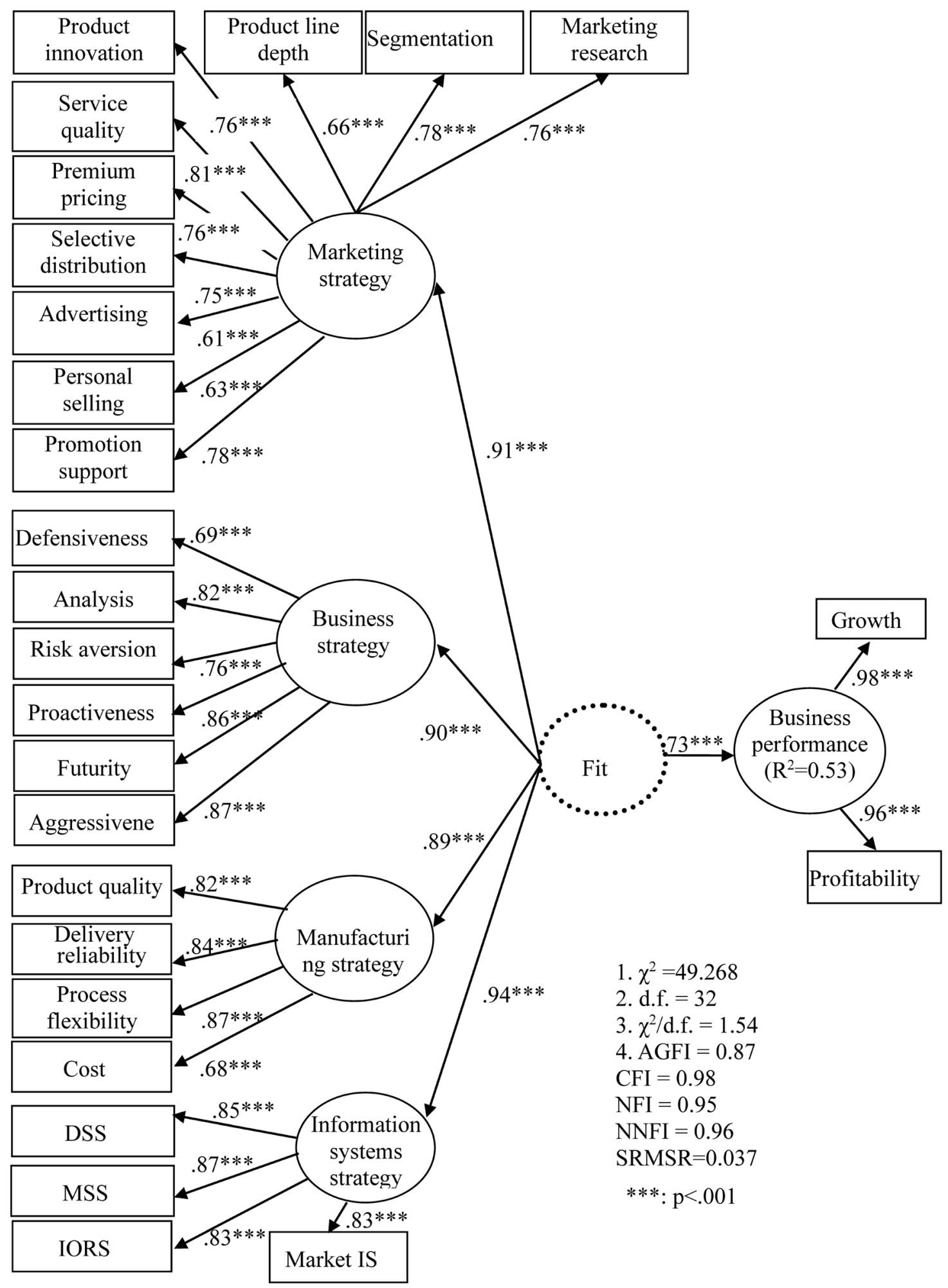

Fig. 2. Results of fit model. 


\section{Conclusion}

Our findings showed significant support for a holistic perspective of fit among business, marketing, manufacturing, and IS strategies when using fit as a covariation approach. The main theoretical basis for marketing, manufacturing, business, and IS strategies of the fit will be an important factor in corporate performance; this is because the fit should be regarded as an overall criterion to follow for a company. This means that firms should take these contingency factors as a whole instead of just focusing on one of the factors when employing the strategy.

The research results show that all four constructs have a strong impact on business performance. It is important to know that fit pays off under certain conditions. Although our proposed constructs have been studied extensively, interfunctional coordination has received scant attention in strategy implementation research, as indicated by Olson et al., ${ }^{(36)}$ and it is still a challenge for most companies to attain a fine degree of interfunctional coordination. Also, with the volatility of the real-world situation, problems could be much more complicated than expected. Therefore, the results of this study only function as a principle while applied to a real scenario. However, to maximize the benefit to the organization, internal cooperation should be taken into consideration while putting it into practice. To further advance the knowledge of the relationship between constructs, a reductionist perspective can be used to further examine or clarify the relationship between them.

Because both internal and external dynamic shifts in the business environment require strategic choices or provide strategic opportunities, resulting changes must be interlinked and assessed continually across all these domains in a systemic manner if firms want to obtain better performance. According to Sabherwal et al., ${ }^{(40)}$ strategic alignment is a dynamic process. Even after alignment is achieved, organizations can fail to adjust their alignment patterns to accommodate environmental changes. Normally, better-performing companies are those that can adjust themselves to a dynamic environment. Our findings also indicate that strategies contribute to business performance via fit. Accordingly, the strategic alignment among strategies implies that companies must think of them holistically when they are planning, making decisions, or budgeting. In the past, a company might have been successful owing to its successful strategy execution; however, it was very likely to fail because of poorly adjusted strategic alignment. Thus, for decision makers, since IoT technology can be applied to improve the management of enterprise performance, recognizing strategies are necessary and critical when limited resources are allocated.

\section{References}

1 W. Skinner: Prod. Oper. Manage. 5 (1996) 3. https://doi.org/10.1111/j.1937-5956.1996.tb00381.x

2 W. Skinner: Harv. Bus. Rev. 47 (1969) 136.

3 T. M. Smith and J. S. Reece: J. Oper. Manage. 17 (1999) 145. https://doi.org/10.1016/S0272-6963(98)00037-0

4 H. Sun and C. Hong: Technov. 22 (2002) 699. https://doi.org/10.1016/S0166-4972(01)00066-9

5 R. Brooksbank: Mark. Intell. Plann. 9 (1991) 17. https://doi.org/10.1108/EUM0000000001112

6 C. H. Liu, C. C. Wang, and L. R. Yang: NTU Manage. Rev. 19 (2008) 103 (in Chinese). https://doi.org/10.6226/ NTURM2008.19.1.103

7 H. Y. Chen: J. Cri. Manage. 11 (2004) 33 (in Chinese). https://doi.org/10.6459/JCM.201403_11.0004 103

8 S. K. Mukhopadhyay and A. Gupta: Euro. J. Mark. 32 (1998) 101. https://doi.org/10.1108/03090569810197499 
9 A. H. Van de Ven and R. Drazin: Res. Organ. Behav. 7 (1985) 333.

10 N. Venkatraman: Acad. Manage. Rev. 14 (1989a) 423. https://doi.org/10.5465/amr.1989.4279078

11 N. Venkatraman and J. E. Prescott: Strategic Manage. J. 11 (1990) 1. https://doi.org/10.1002/smj.4250110102

12 F. Bergeron, L. Raymond, and S. Rivard: Omega 29 (2001) 125. https://doi.org/10.1016/S0305-0483(00)000347

13 N. Venkatraman: Manage. Sci. 35 (1989b) 942. https://doi.org/10.1287/mnsc.35.8.942

14 R. E. Miles and C. C. Snow: Organizational Strategy, Structure, and Process (McGraw-Hill, New York, 1978).

15 M. E. Porter: Competitive Strategy (Free Press, New York, 1980).

16 K. G. Smith, J. P. Guthrie, and M. J. Chen: Organiz. Stud. 10 (1989) 63. https://doi. org/10.1177/017084068901000104

17 N. Venkatraman: Ph. D. Thesis, University of Pittsburgh, Pittsburgh, PA (1985).

18 R. Hayes and S. Wheelwright: Restoring our Competitive Edge (Wiley and Sons, New York, 1984).

19 C. Corbett and L. Van Wassenhove: Calif. Manage. Rev. 35 (1993) 107. https://doi.org/10.2307/41166757

20 S. D. Hunt and C. J. Lambe: Int. J. Manage. Rev. 2 (2000) 17. https://doi.org/10.1111/1468-2370.00029

21 R. Deshpande and F. E. Jr. Webster: J. Mark. 53 (1989) 3. https://doi.org/10.1177/002224298905300102

22 International Telecommunication Union (ITU): https://www.itu.int/net/wsis/tunis/newsroom/stats/TheInternet-of-Things-2005.pdf (accessed March 2019).

23 P. Sethi and S. R. Sarangi: J. Electr. Comput. Eng. 2017 (2017) 1. https://doi.org/10.1155/2017/9324035

24 D. Marchand, W. Kettinger, and J. Rollins: Information Orientation, The Link to Business Performance (Oxford University Press, New York, 2001)

25 Q. Cao and M. J. Schniederjans: Int. J. Prod. Res. 43 (2004) 2915. https://doi.org/10.1080/002075404100016918 84

26 T. Hill: Basingstoke (Macmillan, Basingstoke, 1985).

27 M. Pagell and D. R. Krause: J. Oper. Manage. 17 (1999) 307. https://doi.org/10.1016/S0272-6963(98)00049-7

28 T. Hill: Manufacturing Strategy (Macmillan, Basingstoke, 1995) 2nd ed.

29 D. A. Garvin: Calif. Manage. Rev. Summer 35 (1993) 85. https://doi.org/10.2307/41166756

30 D. E. Schendel and C. W. Hofer: Strategic Management: A New View of Business Policy and Planning (Little Brown, Boston Mass, 1979).

31 P. T. Ward and R. Duray: J. Oper. Manage. 18 (2000) 123. https://doi.org/10.1016/S0272-6963(99)00021-2

32 P. M. Swamidass and W. T. Newell: Manage. Sci. 33 (1987) 509. https://doi.org/10.1287/mnsc.33.4.509

33 S. L. Brown and K. M. Eisenhardt: Competing on the Edge: Strategy as Structured Chaos (Harvard Business School Press, Boston, 1998).

34 M. Abdel-Basset, M. Gunasekaran, M. Mohamed: Future Gener. Comput. Syst. 86 (2018) 614. https://doi. org/10.1016/j.future.2018.04.051

35 C. Fornell and D. E. Larcker: J. Mark. 18 (1981) 39. https://doi.org/10.1177/002224378101800104

36 E. M. Olson, D. F. Slater, and G. T. M. Hult: J. Mark. 69 (2005) 49. https://doi.org/10.1509/jmkg.69.3.49.66362

37 R. Sabherwal and Y. E. Chan: Info. Syst. Res. 12 (2001) 1. https://doi.org/10.1287/isre.12.1.11.9714

38 R. P. Bagozzi and Y. Yi: J. Acad. Mark. Sci. 16 (1988) 74. https://doi.org/10.1007/BF02723327

39 P. M. Podsakoff and D. W. Organ: J. Manage. 12 (1986) 531. https://doi.org/10.1177/014920638601200408

40 R. Sabherwal, R. Hirschheim, and T. Goles: Organ. Sci. 12 (2001) 179. https://doi.org/10.1287/ orsc.12.2.179.10113 